\title{
An approach for estimating the health effects of changes over time in air pollution: an illustration using cardio-respiratory hospital admissions in London
}

\author{
Cathryn Tonne, ${ }^{1,4}$ Sean Beevers, ${ }^{2,4}$ Frank J Kelly, ${ }^{2,4}$ Lars Jarup, ${ }^{3,4}$ Paul Wilkinson, ${ }^{1}$ \\ Ben Armstrong ${ }^{1}$
}

${ }^{1}$ London School of Hygiene and Tropical Medicine, London, UK ${ }^{2}$ Environmental Research Group, King's College London, London, UK

${ }^{3}$ Small Area Health Statistics Unit, Imperial College London, London, UK

${ }^{4}$ MRC-HPA Centre for Environment and Health Imperial College London, London, UK

\section{Correspondence to} Cathryn Tonne, London School of Hygiene and Tropical Medicine, Keppel Street, London WC1E 7HT, UK; cathryn.tonne@lshtm.ac.uk

Accepted 19 October 2009

\section{ABSTRACT}

Objectives First, we present a general analytical approach to estimating the association between medium-term changes in air pollution and health across small areas. As a specific illustration, we then applied the approach to data on London residents from a 4-year period to test whether reductions in traffic-related air pollution were associated with reductions in cardio-respiratory hospital admissions.

Methods A binomial distribution was used to model change in admissions over time in each small area, which was measured as the proportion of admissions in 2003-2004 out of admissions over all study years (2001-2004). Annual average concentrations of nitrogen oxides $\left(\mathrm{NO}_{\mathrm{x}}\right)$ were modelled using an emissions-dispersion model. The association between change in $\mathrm{NO}_{x}$ and change in hospital admissions was estimated using logistic regression and an instrumental variable approach.

Results For some diagnostic groups, suggestive associations between reductions in $\mathrm{NO}_{\mathrm{x}}$ and reductions in admissions were observed, for example, $\mathrm{OR}=0.97$ (95\% Cl 0.96 to 0.99) for an IOR decrease in $\mathrm{NO}_{\mathrm{x}}(3 \mu \mathrm{g} /$ $\mathrm{m}^{3}$ ) and all respiratory admissions. Accounting for spatial dependence attenuated several of the associations; for respiratory admissions, the OR was 1.00 (95\% Cl 0.98 to 1.02), leaving only that for bronchiolitis significant $(\mathrm{OR}=0.91 ; 95 \% \mathrm{Cl} 0.84$ to 0.99$)$. In this particular illustration, the instrumental variable approach did not appear to add information.

Conclusions In this illustration, there was relatively limited power to detect an association between changes in air pollution and hospital admissions over time. However, the analytical approach could deliver more robust estimates of the health effects of changes in air pollution in settings with greater spatial contrast in changes in air pollution over time.

\section{OBJECTIVES}

Ambient air pollution has decreased over the past several decades throughout much of the developed world, ${ }^{1}{ }^{2}$ largely due to increasingly stringent air pollution controls. While there is substantial evidence of an association between air pollution and adverse health outcomes, ${ }^{3} 4$ direct evidence regarding the extent to which control measures have improved public health is limited. ${ }^{5}$ Whether past efforts to control air pollution have resulted in measurable improvements in health, and the likelihood that future efforts will continue to do so, is of great interest. ${ }^{5}$

\section{What this paper adds}

- Few studies have evaluated whether reductions in air pollution on the scale of years are associated with improved population health.

- This study provides a methodological approach for estimating the association between changes over time in air pollution and health outcomes using a binomial distribution to model changes over time in outcomes that are counts.

- We provide a specific illustration of the approach, in which we test whether reductions in traffic pollutants over a 4-year period are associated with reductions in hospital admissions in London.

Although several studies have observed an association between short-term variation in air pollution and hospitalisations for cardio-respiratory disease, ${ }^{6-9}$ few studies have investigated associations with long-term time trends in air pollution. Associations between long-term trends in air pollution and health are frequently confounded by slowly time-varying factors, which are often difficult to measure. ${ }^{10}$ Recent efforts to estimate the association between longer term trends in air pollution and health have therefore applied analytical approaches that specifically aim to minimise confounding. ${ }^{11} 12$ One such approach has been to estimate the association of local trends in air pollution and health outcomes, where time-varying factors would also have to vary across areas in order to be confounders. ${ }^{12-14}$ Such approaches should be less vulnerable to confounding by time trends that have little variability across areas as well as by confounders of purely spatial contrasts in exposure, such as smoking, which change little over time.

This paper has two objectives. First, we present a general analytical approach to estimating the association between changes in air pollution and changes in health outcomes over time across small areas. As one specific illustration, we apply the approach to data on traffic-related air pollution and cardio-respiratory hospital admissions from a 4year period surrounding the introduction of the London Congestion Charge Scheme. We selected this period because the scheme may have led to changes in traffic-related pollutants in only some areas of the city. The scheme, introduced in 
February 2003, charges drivers to travel within a specified zone. The second objective is to test the hypothesis that areas with larger decreases in traffic-related air pollution had larger decreases in cardio-respiratory hospital admissions over time.

\section{METHODS}

Analysis was based on Hospital Episodes Statistics data, which record all episodes of care provided by NHS hospitals in England. ${ }^{15}$ We included patients resident in Greater London who were admitted as an emergency with cardio-respiratory disease as the primary diagnosis during 2001-2004. As a patient may have more than one episode of care during an admission, we restricted analysis to first, finished episodes. To remove duplicates, we included only the first record among those with an identical patient identifier, health care provider code, date of admission and discharge. For records with the same identifier and date of admission, but different date of discharge, we used only the record with the later date of discharge. Admissions within 28 days of discharge from the previous admission for the same patient were excluded since these were likely to be readmissions due to complications rather than independent admissions. We considered admissions for the following primary diagnoses according to ICD-10 codes: all cardiovascular diseases (CVD) (I), ischaemic heart disease (IHD) (I20-I25), stroke (I60-I69), heart failure (I50), all respiratory (J), chronic obstructive pulmonary disease (COPD) (J43-J44), asthma (J45-J46) and bronchiolitis (J21).

Our outcome was the proportion of admissions occurring in 2003-2004 out of admissions in 2001-2004. This proportion can be considered as a measure of change in admissions over time: a proportion of 0.5 represents no change and greater than 0.5 represents an increase over time.

\section{Air pollution exposure}

We considered nitrogen oxides $\left(\mathrm{NO}_{\mathrm{x}}\right)$ as a surrogate for trafficrelated air pollution. Annual average concentrations of $\mathrm{NO}_{\mathrm{x}}$ were modelled for each year from 2001 to 2004 using a hybrid emission-dispersion/regression modelling approach. The model is described in detail elsewhere. ${ }^{16}$ Briefly, ADMS Roads and OSPM were used to model the $\mathrm{NO}_{\mathrm{x}}$ contribution from roadways within a $500 \mathrm{~m}$ buffer around 31 monitoring locations. ADMS3 was used to model the $\mathrm{NO}_{\mathrm{x}}$ contribution from urban background pollution. The ADMS models are second generation Gaussian dispersion models ${ }^{17}{ }^{18}$; OSPM is a street canyon model. ${ }^{19}$ Model input included detailed data on meteorology, traffic flow, speeds and vehicle type. ${ }^{20}$

As a calibration, we then fit a regression model to measurements of $\mathrm{NO}_{\mathrm{x}}$ from 31 monitoring sites. The model included two predictors: the contribution of $\mathrm{NO}_{\mathrm{x}}$ from roadways and the urban background as estimated from the emission-dispersion modelling. The regression model was then used to predict $\mathrm{NO}_{\mathrm{x}}$ concentrations on a uniform $20 \mathrm{~m} \times 20 \mathrm{~m}$ grid. The Spearman correlation between modelled difference in annual means between 2001-2002 and 2003-2004 and measured difference at $24 \mathrm{NO}_{\mathrm{x}}$ monitors not included in the calibration step was 0.80 .

Annual average $\mathrm{NO}_{\mathrm{x}}$ concentrations for each year and ward were calculated as the mean of $\mathrm{NO}_{x}$ concentrations across model grid points falling within each ward's boundary. Change in ward-level $\mathrm{NO}_{\mathrm{x}}$ was defined as the mean concentration in 2001-2002 minus that in 2003-2004. Wards within or adjacent to the boundary of the congestion charging zone (CCZ) were characterised with a binary CCZ indicator.

\section{Socio-demographic variables}

Income deprivation was based on the Index of Multiple Deprivation (IMD) calculated at the level of lower layer super output areas (LSOAs), geographical units with a mean population of $1500 .^{21}$ IMD is a composite score of deprivation made up of seven domains: income, employment, health and disability, education, skills and training, barriers to housing and services, living environment and crime. The income domain is measured as the proportion of residents living in income deprivation; therefore, calculating change over time is more appropriate for the income domain than for others which are based on relative scores. ${ }^{22}$ IMD and income deprivation at the ward level were calculated as population-weighted averages of LSOA deprivation using weights based on 2001 population estimates. ${ }^{23}$ We then calculated a measure of change in deprivation: the proportion of ward residents living in income deprivation in $2001^{24}$ minus the proportion in $2005^{25}$

We constructed demographic measures that reflected wardlevel population at a single time as well as changes over time. We calculated percentages of ward residents by ethnicity in 2001 using the Census 2001 data. ${ }^{26}$ Changes in ward-level population were calculated as the ward mean of 2001-2002 minus that of 2003-2004 for residents aged 65 and older, younger than 20 and for the total population. ${ }^{23}$

\section{Main analysis}

To estimate the association between change in $\mathrm{NO}_{\mathrm{x}}$ and change in admissions, we used a binomial distribution to model the number of admissions in 2003-2004 as a proportion of admissions over all study years (2001-2004) by ward (analogous to modelling the number of events out of total trials). The association between the log odds of 2003-2004 admissions with change in $\mathrm{NO}_{x}$ between 2001-2002 and 2003-2004 was estimated using Proc Logistic in the SAS software package. We adjusted for potential confounders that were independent predictors of change in admissions and correlated with changes in $\mathrm{NO}_{\mathrm{x}}$ : average IMD in 2001, change in proportion of residents living in income deprivation, change in number of residents aged 65 years and older, and percentages of residents who were nonwhite, black, Asian and Chinese. All covariates were continuous and modelled with a linear functional form.

The unit of analysis in the logistic model was the ward $(n=628)$, a census based geographical unit that is nested within London boroughs $(n=33)$. Wards within the same borough are likely to have more similar hospitalisation rates compared to wards in other boroughs, which may result in incorrect effect estimates and standard errors. We therefore conducted an analysis to account for this spatial dependence by including a random intercept for each borough using Proc Glimmix. To describe the extent of such clustering we also estimated the intraclass correlation, which indicates the proportion of the total variability in the outcome at the borough level.

\section{Instrumental variable analysis}

We further evaluated whether charging zone status could be used effectively as an instrumental variable to test the hypothesis stated in our second objective. An instrumental variable estimate may be less vulnerable to confounding than the association using modelled change in $\mathrm{NO}_{\mathrm{x}}$ as exposure if several assumptions are met. ${ }^{27}$ These assumptions are primarily that (1) the instrumental variable is associated with changes in $\mathrm{NO}_{\mathrm{x}},(2)$ the instrumental variable affects changes in admissions only through changes in $\mathrm{NO}_{\mathrm{x}}$ and (3) the instrumental variable is not associated with other unmodelled predictors of change in 
admissions. We evaluated whether each assumption was reasonable using charging zone status as an instrumental variable. Specifically, we used a two-sample t test to test the association between the CCZ indicator and change in $\mathrm{NO}_{\mathrm{x}}$. Assumptions 2 and 3 are not empirically verifiable; therefore, we evaluated them indirectly. We assessed the strength of association between the CCZ indicator and changes in admissions that was not mediated by changes in $\mathrm{NO}_{\mathrm{x}}$. To evaluate the third assumption, we compared observable socio-demographic variables for wards within and outside the charging zone.

We then used a 'pseudo two-stage least squares' method to estimate the instrumental variable association between changes in $\mathrm{NO}_{\mathrm{x}}$ and admissions. In the first stage, we regressed change in $\mathrm{NO}_{\mathrm{x}}$ on the CCZ indicator (and potential confounders in the fully adjusted model) to estimate an adjusted mean difference in change in $\mathrm{NO}_{\mathrm{x}}$ inside minus outside the zone. In the second stage, we regressed the proportion of admissions in 2003-2004 on predicted values from the first stage (and potential confounders in the adjusted model). Although in linear models, instrumental variable estimates are consistent, with non-linear link functions they may be biased. ${ }^{28}$ Nonetheless, the bias is often small and two-stage logistic methods have been shown in practice to provide similar results as generalised method of moments estimation. ${ }^{29}$ In this application, the proportions predicted by the logistic models were near 0.5 (5th percentile: 0.48; 95th percentile: 0.55 ); therefore, the link function is very nearly linear and the bias is expected to be small.

\section{RESULTS}

Across London, $\mathrm{NO}_{\mathrm{x}}$ concentrations decreased by $3.5 \mu \mathrm{g} / \mathrm{m}^{3}$ between the two time periods (table 1). The average $\mathrm{NO}_{\mathrm{x}}$ concentration in 2001-2002 was $77 \mu \mathrm{g} / \mathrm{m}^{3}$ (SD $17 \mu \mathrm{g} / \mathrm{m}^{3}$ ). Across wards, there was relatively modest variation in decreases in $\mathrm{NO}_{\mathrm{x}}$ over time; the difference between the 90th and 10th percentile was $4.7 \mu \mathrm{g} / \mathrm{m}^{3}$. NOx concentrations increased in $<5 \%$ of wards, particularly in the western half of the city (figure 1). For wards within or adjacent to the CCZ boundary, $\mathrm{NO}_{\mathrm{x}}$ decreased by $5.8 \mu \mathrm{g} / \mathrm{m}^{3}$. On average, there was an unadjusted increase in admissions for respiratory disease, COPD and asthma (table 1). However, there appeared to be little or no unadjusted change over time for other cardio-respiratory disease categories. The greatest variation across wards in the proportion of hospital admissions occurring in 2003-2004 was observed for bronchiolitis (90th-10th percentile $=0.44)$ and heart failure (90th-10th percentile $=0.26$ ).

Table 2 presents correlations between decreases in $\mathrm{NO}_{\mathrm{x}}$ concentration, deprivation, population and ethnicity. Wards with the largest decrease in $\mathrm{NO}_{\mathrm{x}}$ had increasing income deprivation over time, higher deprivation in 2001, a decreasing number of residents aged 65 years or older and a higher percentage of black residents.

The relative odds of hospital admissions occurring in 2003-2004 per interquartile range (IOR; $2.66 \mu \mathrm{g} / \mathrm{m}^{3}$ ) decrease in $\mathrm{NO}_{\mathrm{x}}$ is presented according to diagnostic group in table 3 . After adjusting for potential confounders, an IOR decrease in $\mathrm{NO}_{x}$ was associated with a $9 \%(95 \%$ CI $2 \%$ to $15 \%)$ decrease in the odds of admission for bronchiolitis in the main analysis. Similarly, decreasing $\mathrm{NO}_{\mathrm{x}}$ was associated with decreasing admissions for respiratory disease and heart failure. Further adjustment for change in total population or in those aged 20 or younger between 2001-2002 and 2003-2004 did not alter the results of the main analysis. However, accounting for spatial dependence at the borough level substantially attenuated the associations. Of the fully adjusted estimates, only the association for bronchiolitis, which had the least spatial dependence, remained statistically significant. Much of the total variation in the proportion of admissions in 2003-04 was between boroughs, particularly for all cardiovascular and respiratory admissions.

The average change in $\mathrm{NO}_{\mathrm{x}}$ concentration differed significantly between the CCZ and non-CCZ wards: mean difference was $2.5 \mu \mathrm{g} / \mathrm{m}^{3}$ (SD 1.8), $\mathrm{p}<0.0001$ from $\mathrm{t}$ test. However, the $\mathrm{R}^{2}$ was only 0.10 in a model regressing change in $\mathrm{NO}_{\mathrm{x}}$ on charging zone status, indicating that the instrumental variable was weakly associated with exposure. Furthermore, only for bronchiolitis was charging zone status significantly associated with the proportion of admissions in 2003-2004 after adjusting for confounding variables (table 4). This association was attenuated to non-significance after including change in $\mathrm{NO}_{\mathrm{x}}$, providing little evidence against the assumption that the instrumental variable was associated with the outcome only through its association with exposure. Although we could not directly test whether there were unmeasured differences between the CCZ wards and the rest of London, we observed significant differences between wards within and outside the zone for several observable socio-demographic variables (table 5). For example, on average, wards within the zone were more deprived in 2001 and had a larger increase in total population over time. The

Table 1 Distribution across wards in decreases in average NOx concentration from 2001-2002 to 2003-2004 and in the proportion of admissions in 2001-2004 occurring in 2003-2004

\begin{tabular}{|c|c|c|c|c|c|c|c|}
\hline & \multirow[b]{2}{*}{$\mathbf{N}$} & \multirow[b]{2}{*}{ Mean (SD) } & \multicolumn{5}{|c|}{ Percentile } \\
\hline & & & $\overline{\text { 10th }}$ & 25th & 50th & 75th & 90th \\
\hline Decrease in $\mathrm{NO}_{\mathrm{x}}\left(\mu \mathrm{g} / \mathrm{m}^{3}\right)$ & Wards & & & & & & \\
\hline Greater London & 628 & $3.48(1.90)$ & 1.1 & 2.00 & 3.52 & 4.66 & 5.75 \\
\hline Non-CCZ & 589 & $3.32(1.78)$ & 1.04 & 1.93 & 3.33 & 4.50 & 5.50 \\
\hline Proportion of admissions in 2003-2004 & Admissions* & & & & & & \\
\hline Cardiovascular disease & 206720 & $0.51(0.05)$ & 0.46 & 0.48 & 0.51 & 0.54 & 0.57 \\
\hline Heart failure & 27953 & $0.50(0.11)$ & 0.37 & 0.43 & 0.50 & 0.56 & 0.63 \\
\hline Respiratory disease & 201033 & $0.54(0.06)$ & 0.48 & 0.50 & 0.53 & 0.56 & 0.60 \\
\hline COPD & 39685 & $0.54(0.10)$ & 0.43 & 0.48 & 0.53 & 0.61 & 0.67 \\
\hline Asthma & 32128 & $0.54(0.10)$ & 0.42 & 0.47 & 0.54 & 0.60 & 0.66 \\
\hline Bronchiolitis & 8206 & $0.50(0.18)$ & 0.29 & 0.38 & 0.50 & 0.61 & 0.73 \\
\hline
\end{tabular}

*Column presents the number of hospital admissions according to disease group; however, the proportion of admissions occurring in $2003-2004$ is distributed across 628 wards. $\mathrm{CCZ}$, congestion charging zone; COPD, chronic obstructive pulmonary disease; CVD, cardiovascular disease; IHD, ischaemic heart disease; $\mathrm{NO}_{\mathrm{x}}$, oxides of nitrogen. 

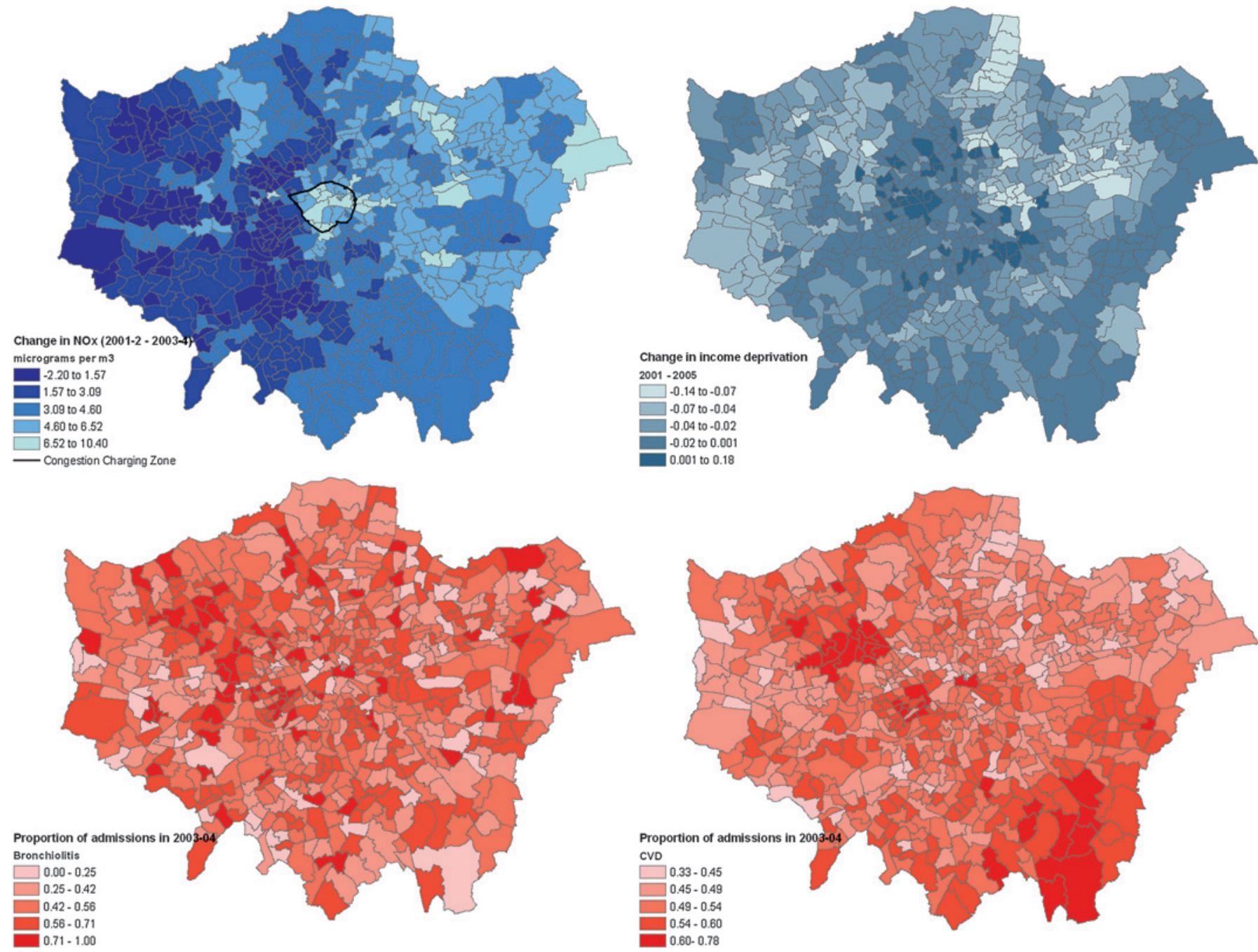

Figure 1 Ward level change in concentration of $\mathrm{NO}_{x}$; change in income deprivation between 2001 and 2005; proportion of 2001-2004 admissions for bronchiolitis and cardiovascular disease occurring in 2003-2004.

instrumental variable estimates were broadly comparable to the estimates from the main analysis but had much wider confidence intervals (table 3).

\section{DISCUSSION}

We presented a general analytical approach to investigate whether spatial variation in medium-term changes in air pollution were associated with changes in the occurrence of a health outcome. This approach is particularly useful for outcomes which are counts (eg, hospital admissions or deaths), since the difference between counts may be negative and therefore not Poisson distributed. By comparison, changes over time in normally distributed outcomes can be modelled in a relatively straightforward fashion as the difference between the outcome at two points in time.

In the main analysis, wards with larger decreases in $\mathrm{NO}_{x}$ concentration had, on average, larger decreases (or smaller increases) in admissions for heart failure, respiratory disease and

Table 2 Spearman correlations between ward-level reductions in $\mathrm{NO}_{\mathrm{x}}$ and ward-level socio-demographic variables

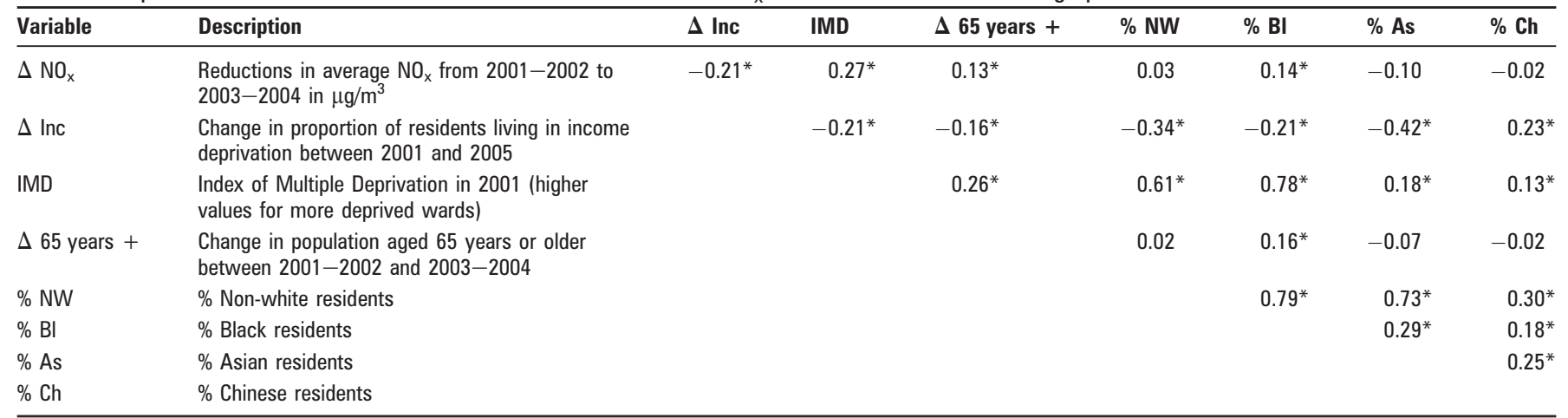


Table 3 Relative odds (95\% Cl) of 2001-2004 hospital admissions occurring in 2003-2004 per interquartile range $\left(2.66 \mu \mathrm{g} / \mathrm{m}^{3}\right)$ decrease in $\mathrm{NO}_{\mathrm{x}}$ : (a) main analysis, (b) main analysis accounting for spatial dependence at the borough level and (c) using congestion charging zone as an instrumental variable

\begin{tabular}{|c|c|c|c|c|c|c|c|c|c|c|c|c|c|}
\hline \multirow{3}{*}{$\begin{array}{l}\text { Diagnostic } \\
\text { group }\end{array}$} & \multicolumn{4}{|c|}{ (a) Main analysis } & \multicolumn{5}{|c|}{ (b) Spatial dependence } & \multicolumn{4}{|c|}{ (c) Instrumental variable analysis } \\
\hline & \multicolumn{2}{|c|}{ Unadjusted } & \multicolumn{2}{|c|}{ Adjusted* } & \multicolumn{2}{|c|}{ Unadjusted } & \multicolumn{3}{|c|}{ Adjusted* } & \multicolumn{2}{|c|}{ Unadjusted } & \multicolumn{2}{|c|}{ Adjusted* } \\
\hline & $\overline{\mathbf{O R}}$ & $95 \% \mathrm{Cl}$ & $\overline{\mathbf{O R}}$ & $95 \% \mathrm{Cl}$ & $\overline{\mathbf{O R}}$ & $95 \% \mathrm{Cl}$ & $\overline{\mathbf{O R}}$ & $95 \% \mathrm{Cl}$ & ICC & $\overline{\mathbf{O R}}$ & $95 \% \mathrm{CI}$ & $\mathbf{O R}$ & $95 \% \mathrm{Cl}$ \\
\hline IHD & 1.01 & 0.99 to 1.03 & 1.01 & 0.99 to 1.04 & 0.99 & 0.96 to 1.02 & 0.99 & 0.96 to 1.02 & 0.28 & 0.95 & 0.88 to 1.02 & 0.95 & 0.88 to 1.03 \\
\hline Stroke & 0.95 & 0.89 to 1.00 & 1.00 & 0.97 to 1.04 & 1.00 & 0.96 to 1.04 & 1.02 & 0.98 to 1.07 & 0.14 & 0.92 & 0.83 to 1.02 & 0.99 & 0.88 to 1.10 \\
\hline Heart failure & 0.94 & 0.91 to 0.97 & 0.94 & 0.90 to 0.97 & 0.96 & 0.91 to 1.00 & 0.96 & 0.91 to 1.01 & 0.19 & 0.88 & 0.79 to 1.00 & 0.92 & 0.81 to 1.05 \\
\hline Asthma & 0.97 & 0.94 to 1.00 & 1.02 & 0.98 to 1.05 & 0.99 & 0.95 to 1.04 & 1.00 & 0.96 to 1.05 & 0.23 & 0.84 & 0.75 to 0.93 & 0.92 & 0.82 to 1.04 \\
\hline Bronchiolitis & 0.94 & 0.88 to 1.00 & 0.91 & 0.85 to 0.98 & 0.92 & 0.85 to 1.00 & 0.91 & 0.84 to 0.99 & 0.06 & 0.91 & 0.74 to 1.22 & 0.79 & 0.63 to 0.98 \\
\hline
\end{tabular}

${ }^{*}$ Adjusted for IMD in 2001, change in proportion of residents living in income deprivation between 2001 and 2005 , change in population aged 65 years or older between 2001 and $2004, \%$ non white, \% black (black Caribbean, black African, black other), \% Asian (Indian, Pakistani, Bangladeshi, Asian other) and \% Chinese residents.

COPD, chronic obstructive pulmonary disease; ICC, intraclass correlation; IHD, ischaemic heart disease; IMD, Index of Multiple Deprivation; $\mathrm{NO}_{\mathrm{x}}$, oxides of nitrogen.

bronchiolitis after adjusting for potential confounders. However, there was substantial spatial dependence in the data, and only the adjusted association for bronchiolitis remained after accounting for the dependence. That we observed a significant association consistent with our hypothesis for bronchiolitis, but not other disease groups, may reflect the greater variation in our outcome for bronchiolitis and thus better statistical power. Whether the association for bronchiolitis could be causal rather than chance requires further investigation.

While studies focussing on contrasts in local changes in exposure may be less vulnerable to confounding by timeinvariant factors than purely spatial contrasts in exposure, confounding by time-invariant factors is still a concern. For example, in our data, the correlation between IMD for 2001 and annual average ward-level $\mathrm{NO}_{\mathrm{x}}$ in 2001 was 0.53, while the correlation with change in ward-level $\mathrm{NO}_{\mathrm{x}}$ was 0.27 . Whether time-invariant factors are proxies for other variables that change over time or are important in their own right requires further investigation. We observed large differences in several sociodemographic variables between wards within versus outside the charging zone (table 5), indicating that wards with the largest decrease in $\mathrm{NO}_{\mathrm{x}}$ are different in many respects from wards with smaller decreases in $\mathrm{NO}_{\mathrm{x}}$. Although we were able to adjust for several socio-demographic variables, and used an analysis specifically designed to reduce confounding, residual

Table 4 Odds of 2001-2004 hospital admissions occurring in 2003-2004 for wards within the charging zone relative to wards outside the zone (a) unadjusted and (b) adjusted for change in $\mathrm{NO}_{\mathrm{x}}$

\begin{tabular}{|c|c|c|c|c|}
\hline \multirow{2}{*}{$\begin{array}{l}\text { Diagnostic } \\
\text { group }\end{array}$} & \multicolumn{2}{|c|}{ (a) Unadjusted } & \multicolumn{2}{|c|}{ (b) Adjusted for $\Delta \mathrm{NO}_{\mathrm{x}}$} \\
\hline & $\overline{\mathbf{O R}}$ * & $95 \% \mathrm{Cl}$ & $\overline{\mathbf{O R}}{ }^{*}$ & $95 \% \mathrm{CI}$ \\
\hline $\begin{array}{l}\text { Cardiovascular } \\
\text { disease }\end{array}$ & 0.98 & 0.94 to 1.02 & 0.98 & 0.94 to 1.03 \\
\hline IHD & 0.95 & 0.89 to 1.02 & 0.94 & 0.87 to 1.01 \\
\hline Stroke & 0.99 & 0.89 to 1.10 & 0.98 & 0.88 to 1.10 \\
\hline Heart failure & 0.93 & 0.83 to 1.05 & 0.98 & 0.86 to 1.10 \\
\hline $\begin{array}{l}\text { Respiratory } \\
\text { disease }\end{array}$ & 1.01 & 0.97 to 1.05 & 1.03 & 0.99 to 1.07 \\
\hline COPD & 1.00 & 0.92 to 1.10 & 1.02 & 0.94 to 1.12 \\
\hline Asthma & 0.93 & 0.84 to 1.03 & 0.92 & 0.82 to 1.02 \\
\hline Bronchiolitis & 0.80 & 0.65 to 0.98 & 0.85 & 0.68 to 1.05 \\
\hline
\end{tabular}

*Estimates in both (a) and (b) are adjusted for potential confounders: IMD in 2001, change in proportion of residents living in income deprivation between 2001 and 2005, change in population aged 65 years or older between 2001 and 2004,\% non-white, \% black (black Caribbean, black African, black other), \% Asian (Indian, Pakistani, Bangladeshi, Asian other) and \% Chinese residents.

$\mathrm{COPD}$, chronic obstructive pulmonary disease; IHD, ischaemic heart disease; $\mathrm{NO}_{\mathrm{x}}$, oxides of nitrogen. confounding of our estimated odds ratios by unmeasured sociodemographic variables cannot be ruled out.

In our illustration, unmeasured changes over time in individual hospitals' admission practices are also likely to be important determinants of the outcome since they would affect a given hospital's catchment area rather than London overall. Applying the proposed approach to other routinely collected health outcomes, such as mortality, would avoid possible confounding due to this source. Our choice to investigate hospital admissions rather than deaths was based on power considerations, as there are approximately 70000 more hospital admissions per year in London compared to deaths from cardiorespiratory disease.

In the specific context of the congestion charge, the introduction of the scheme did not fully meet the assumptions necessary to be an effective instrumental variable. Our analysis indicated that charging zone status was associated with exposure, although the association was relatively weak. There were significant differences between several observable socio-demographic variables in wards within and outside the zone Although not a formal test, this suggests that wards in the

Table 5 Observable predictors of change in hospital admissions over time according to congestion charging zone (CCZ) status

\begin{tabular}{|c|c|c|c|}
\hline Variable & $\begin{array}{l}\text { Mean within } \\
\text { CCZ } \\
(n=39)\end{array}$ & $\begin{array}{l}\text { Mean outside } \\
\text { CCZ } \\
(\mathrm{n}=589)\end{array}$ & $\begin{array}{l}\text { t Statistic } \\
\text { (p value) }\end{array}$ \\
\hline $\begin{array}{l}\text { Change in proportion of } \\
\text { residents living in income } \\
\text { deprivation between } 2001 \\
\text { and } 2005\end{array}$ & -0.009 & -0.028 & $-3.25(0.002)$ \\
\hline $\begin{array}{l}\text { Index of Multiple Deprivation } \\
\text { in } 2001 \text { (higher values for } \\
\text { more deprived wards) }\end{array}$ & 33.9 & 24.3 & $-4.76(<0.0001)$ \\
\hline $\begin{array}{l}\text { Change in total population } \\
\text { between } 2001-2002 \text { and } \\
2003-2004\end{array}$ & -264 & -41 & $4.10(0.0002)$ \\
\hline $\begin{array}{l}\text { Change in population aged } \\
65 \text { years or older between } \\
2001-2002 \text { and } 2003-2004\end{array}$ & 13 & 9 & $-0.61(0.55)$ \\
\hline $\begin{array}{l}\text { Change in population aged } \\
<20 \text { years between } \\
2001-2002 \text { and } 2003-2004\end{array}$ & -19 & -9 & $0.69(0.49)$ \\
\hline$\%$ Non-white residents & 30.9 & 27.9 & $-1.32(0.19)$ \\
\hline \% Black residents & 11.1 & 10.4 & $-0.48(0.63)$ \\
\hline$\%$ Asian residents & 11.8 & 11.9 & $0.06(0.95)$ \\
\hline$\%$ Chinese residents & 2.2 & 1.1 & $-7.05(<0.0001)$ \\
\hline $\begin{array}{l}\% \text { Residents aged } 65 \text { years or } \\
\text { older }\end{array}$ & 11.2 & 12.6 & $2.39(0.02)$ \\
\hline
\end{tabular}


charging zone are different from remaining wards in several respects and might be so for factors for which we did not have data. The third assumption required for an instrumental variable to deliver less biased estimates would not be met if such unmeasured factors were associated with changes in admissions. A further limitation of the instrumental variable estimates is their relatively large standard errors, a common feature of the method and a reflection of the weakness of the association between the charging zone and change in $\mathrm{NO}_{\mathrm{x}}{ }^{30}$

Several limitations of the specific illustration we chose warrant consideration. We selected data from a period surrounding the introduction of a traffic management scheme that may have led to changes in pollutants in only some areas of London in order to maximise spatial contrast in changes in traffic-related air pollution. Nonetheless, the variations in modelled changes in $\mathrm{NO}_{\mathrm{x}}$ were small, limiting our power to detect associations. Modelled changes in exposure were also small relative to modelling error. The timing between a reduction in long-term exposure to air pollution and a possible reduction in the occurrence of cardio-respiratory hospitalisations remains uncertain; the 4-year period we considered may not be sufficiently long.

Relatively few studies have investigated the impact of decreasing medium- to long-term trends in air pollution on health because of the potential for these associations to be confounded by slowly time-varying factors. These few studies have developed or applied analytical approaches that specifically minimise confounding. To date, none have evaluated hospital admissions. Janes et al decomposed the association between trends in fine particles and mortality in US counties into the association between (1) national trends and (2) county-specific trends. ${ }^{12}$ The second, which indicates whether counties with steeper declines in particles also have steeper declines in mortality, was expected to be less confounded. Strong associations were observed between national trends in particles and mortality, but no association was observed for the countyspecific trends. Illustrating another approach, Chay et al used non-attainment status designated under the 1970 Clean Air Act as an instrumental variable. ${ }^{11}$ Non-attainment status of the county was associated with reductions in total suspended particles, although no association with reductions in adult mortality was observed. Other studies investigated whether cities with the largest decrease in particles had the largest reduction in premature mortality, ${ }^{14}{ }^{31}$ arguing that long-term trends in mortality were unlikely to explain their results since such trends would affect all cities, rather than have a differential effect in cities with larger reductions in pollution.

In conclusion, we developed an analytical approach to assess the association between changes in air pollution and health outcomes over time across small areas. In this illustration, which was restricted to a relatively short follow-up period and single metropolitan area, we had limited statistical power. We observed a significant association between reductions in $\mathrm{NO}_{\mathrm{x}}$ and reductions in admissions only for bronchiolitis. Nonetheless, the analytical approach could deliver more robust estimates of the health effects of changes in air pollution if data were available over a longer period or with greater contrasts in changes in air pollution.

Funding This work was supported by the U.S. National Institute of Environmental Health Sciences (F32ES015432), and the Health Effects Institute.

Competing interests None.

Provenance and peer review Not commissioned; externally peer reviewed.

\section{REFERENCES}

1. DEFRA, Air Quality Expert Group. What are the main trends in particulate matter in the United Kingdom? London, United Kingdom: DEFRA, 2005. (Chapter 7).

2. US EPA. Air quality criteria for particulate matter. Washington, DC: EPA, 2004, (600/ P-99/002aF-bF).

3. Krewski D, Burnett R, Goldberg M, et al. Reanalysis of the Harvard six cities study and the American Cancer Society Study of particulate Air Pollution and Mortality. Boston, MA: Health Effects Institute, 2000.

4. Committee on the Medical Effects of Air Pollutants. Cardiovascular disease and air pollution. London, United Kingdom: COMEAP, Department of Health, 2006.

5. Health Effects Institute. Assessing the health impact of air quality of air quality regulations: concepts and methods for accountability research. Boston, MA: Health Effects Institute, 2003.

6. Schwartz J. Air pollution and hospital admissions for heart disease in eight U.S. counties. Epidemiology 1999;10:17-22.

7. Wellenius GA, Schwartz J, Mittleman MA. Particulate air pollution and hospital admissions for congestive heart failure in seven United States cities. Am J Cardiol 2006;97:404-8.

8. Andersen ZJ, Wahlin P, Raaschou-Nielsen 0, et al. Ambient particle source apportionment and daily hospital admissions among children and elderly in Copenhagen. J Expos Sci Environ Epidemiol 2007;17:625-36.

9. Dominici $\mathbf{F}$, Peng RD, Bell ML, et al. Fine particulate air pollution and hospital admission for cardiovascular and respiratory diseases. JAMA 2006;295:1127-34

10. Pope CA, Burnett RT. Confounding in air pollution epidemiology - the broader context. Epidemiology 2007;18:424-6.

11. Chay K, Dobkin C, Greenstone M. The clean air act of 1970 and adult mortality. $J$ Risk Uncertain 2003;27:279-300.

12. Janes H, Dominici F, Zeger SL. Trends in air pollution and mortality-an approach to the assessment of unmeasured confounding. Epidemiology 2007;18:416-23.

13. Chay KY, Greenstone M. The impact of air pollution on infant mortality: evidence from geographic variation in pollution shocks induced by a recession. Quart $J$ Econ 2003;118:1121-67.

14. Pope CA III, Ezzati M, Dockery DW. Fine-particulate air pollution and life expectancy in the United States. N Engl J Med 2009;360:376-86.

15. Hospital Episode Statistics, UK Department of Health 2008. http://www hesonline.nhs.uk/Ease/servlet/ContentServer?sitelD=1937 (accessed 15 Dec 2007).

16. Tonne C, Beevers S, Armstrong BG, et al. Air pollution and mortality benefits of the London Congestion Charge: spatial and socioeconomic inequalities. Occup Environ Med 2008;65:620-7

17. Cambridge Environmental Research Consultants. ADMS Roads Users Guide Version 2.0. Cambridge, UK: Cambridge Environmental Research Consultants, 2003.

18. Cambridge Environmental Research Consultants. ADMS 3 Users Guide Version 3.2. Cambridge, UK: Cambridge Environmental Research Consultants, 2004.

19. Berkowicz R. OSPM - a parameterised street pollution model. Environ Monit Assess 2000;65:323-31.

20. Greater London Authority. London Atmospheric Emissions Inventory 2003 Second Annual Report. London, UK: Greater London Authority, 2006.

21. Office for National Statistics. Super output areas, 2006. http://www.statistics. gov.uk/geography/soa.asp (accessed 10 Nov 2007).

22. Communities and Neighbourhoods. Using the English Indices of Deprivation 2007 2007. http://www.communities.gov.uk/documents/communities/doc/615986.doc (accessed 5 Jan 2008).

23. Office for National Statistics. Ward mid-year population estimates for England and Wales (experimental). 2008. http://www.statistics.gov.uk/statbase/Product.asp? vink $=13893$ gMore $=Y$ (accessed 15 Jan 2008).

24. Communities and Local Governments. The English Indices of Deprivation 2004 Summary (revised). 2007. http://www.communities.gov.uk/archived/ general-content/communities/indicesofdeprivation/216309/ (accessed 10 Nov 2007).

25. Communities and Local Governments. The English Indices of Deprivation 2007: Summary. Vol. 2008, 2007. http://www.communities.gov.uk/communities/ neighbourhoodrenewal/deprivation/deprivation07/ (accessed 5 Jan 2008).

26. Office for National Statistics. 2001 Census: Standard Area Statistics (England and Wales). Census Dissemination Unit, MIMAS. 2007. http://cdu.mimas.ac.uk// index.htm (accessed 17 Feb 2007).

27. Hernan MA, Robins JM. Instruments for causal inference - An epidemiologist's dream? Epidemiology 2006;17:360-72.

28. Johnston KM, Gustafson P, Levy AR, et al. Use of instrumental variables in the analysis of generalized linear models in the presence of unmeasured confounding with applications to epidemiological research. Stat Med 2008;27:1539-56.

29. Rassen JA, Schneeweiss S, Glynn RJ, et al. Instrumental variable analysis for estimation of treatment effects with dichotomous outcomes. Am J Epidemiol 2009:169:273-84.

30. Martens EP, Pestman WR, de Boer A, et al. Instrumental variables application and limitations. Epidemiology 2006;17:260-7.

31. Laden F, Schwartz J, Speizer FE, et al. Reduction in fine particulate air pollution and mortality-extended follow-up of the Harvard six cities study. Am J Respir Crit Care Med 2006;173:667-72 